\title{
Is there a Cumulative Effect of Selection?
}

\author{
Data from the Study of Fecundity in the Domestic Fowl1). \\ By Raymond Pearl, Ph. D. and Frank M. Surface, Ph. D.
}

\section{Introduction.}

The purpose of this paper is to present brie $r$ certain results of a series of selection experiments ${ }^{2}$ ) which has been carried on at the Maine Experiment Station with poultry during the past eleven years having as its purpose to get data on the question which stands as the title of this paper. The specific character which was the object of selection in these experiments was "egg production" or fecundity. This is a character which is particularly suited to selection studies because it is expressed in integral units and on that account it is possible to observe with much exactness and precision the effect of any selective or other experimental procedures.

Before undertaking specifically the discussion of our results it will be well to review very briefly the history of biological opinion regarding the question of whether there is a definitely cumulative effect of selection. It has long been held as one of the most fundamental principles of practical breeding, both with animals and plants, that the surest way in which to bring about improvement in a strain was to select for breeding the individuals of superior quality Certainly until comparatively recently a great many breeders would

1) Papers from, the Biological Laboratory of the Maine Agricultural Experiment Station. Orono, Maine, U. S. A. No. I2.

2) The detailed report of the results of these experiments will be found in the following publications by the present writers:

(a) A Biometrical Study of Egg Production in the Domestic Fowl. Part I Variation in Annual Egg Production. Bur. of Animal Industry, U. S. Dept. of Agriculture, Bulletin I Io, Igog.

(b) Data on the Inheritance of Fecundity Obtained from the Records of Egg Production of the Daughters of "200-Egg" Hens. Maine Agricultural Experiment Station Bulletin I66, pp. 49-84, I909. 
have said that this was the only absolutely certain way to insure improvement. It is merely a statement of fact to say that even now the vast majority of practical breeders hold to this opinion. It is embodied in many maxims of practical breeding such as "breed from the best to get the best", "like produces like", etc.

Widespread as it has always been among practical breeders this view as to the effect of selection can hardly be said to have acquired a definite scientific status until after the publication of the "Origin of Species". A great deal of the material which Darwin used in this work and also in the "Variation of Animals and Plants under Domestication" was obtained from the records and published statements of practical agricultural breeders. Darwin himself was firmly convinced of the general truth of the contention that improvement in domesticated animals had been brought about chiefly by the continued selection of small, favorable variations. This is sufficiently shown by the following statement: "We cannot suppose that all the breeds were suddenly produced as perfect and as useful as we now see them; indeed, in many cases we know that this has not been their history. The key is man's power of accumulative selection: nature gives successive variations; man adds them up in certain directions useful to him. In this sense he may be said to have made for himself useful breeds."I) Still more definite is the following: "If selection consisted merely in separating some very distinct variety, and breeding from it, the principle would be so obvious as hardly to be worth notice; but its importance consists in the great effect produced by the accumulation in one direction, during successive generations, of differences absolutely inappreciable by an uneducated eye - differences which I for one have vainly attempted to appreciate." ${ }^{2}$ )

The view that there was in practically all cases of the improvement of domesticated plants and animals by breeding a definitely cumulative effect of selection may be said to have held the field almost undisputed until the publication of de Vries' "Mutationstheorie." This investigator's searching critique of the data furnished by the results of agricultural breeding work showed clearly enough that certainly all the improvement which has taken place in plants and animals under domestication can not be explained as a cumulative result of the continued selection of favorable variations.

1) Origin of Species. Chapter I, p. 25.

2) Loc. cit. p. 26. 
During the last few years there has been a considerable amount of careful and critical experimental work done to test the method of action and limitations of continued selection in breeding. In particular reference should be made in this connection to the work of the Svalöf Experiment Station in practical plant breding; $\left.{ }^{1}\right)$ to the experimental work of J oh annsen ${ }^{2}$ ) with beans, and to the extensive and thorough investigations of Jennings ${ }^{3}$ ) on selection in Paramecium. The broad general result reached by these workers may be fairly stated as follows: From a mixed "general" population it is possible by a single selection to isolate pure strains ("pure lines," "homozygote strains," "pure races") which will breed true and not revert to the mean of the general population from which they were isolated, regardless of whether further selection is practiced or not. It is impossible to demonstrate any cumulative effect of continued selection within the pure strain. Continued breeding from the extreme individuals of such a pure strain ("fluctuating" variants) does not change the mean of that strain. From these considerations it follows that it will be difficult or impossible to make any definite and permanent change in the mean of a general population simply and solely by continued selection of extreme individuals, because in the vast majority of cases such individuals will be extreme fluctuating variants rather than mutants. Correns") says (loc. cit. p. 5I): "Die Zuchtwahl, die künstliche sowohl wie die natürliche, hat, auf die individuellen Varianten angewandt, jedenfalls keinen bleibenden Erfolg, wahrscheinlich gar keinen." J ennings, in concluding his paper, makes a statement of similar import. He says (loc. cit. p. 522): "Certainly, therefore, until some one can show that selection is effective within

1) For summaries of this work in languages more generally read than Swedish cf.: (a) Ulander, A., Die schwedische Pflanzenzüchtung zu Svalöf. Eine kurze Darstellung. Jour. f. Landwirtsch. Bd. 54, 1906, pp. 105-124. P1. II-VII (b) Constantin, J. Le transformisme appliqué a l'agriculture. Paris (Alcan) 1906. Chap. IX. (Le Laboratoire de Svalöf et la Mutation), pp. 7I-96. (c) De Vries, H. Plant Breeding. Chicago (Open Court) 1907, Chap. II (The Discovery of the Elementary Species of Agricultural Plants by Hjalmar Nilsson) pp. 29-106.

2) Johannsen, W. Uber Erblichkeit in Populationen und in reinen Linien. Jena (Fischer) 1903, Pp. 68.

3) Jennings, H. S. Heredity, Variation and Evolution in Protozoa. II. Heredity and Variation of Size and Form in Paramecium with Studies of Growth, Enviromental Action and Selection. Proc. Amer. Phil. Soc. Vol. XVI, pp. 393-546. 1908.

4) Correns, C. Experimentelle Untersuchungen über die Entstehung der Arten auf botanischem Gebiet. Arch. rass. u. gesellsch. Biol. Bd. I, pp. 27-52. I904. 
pure lines, it is only a statement of fact to say that all the experimental evidence we have is against this."

The bulk of the evidence which has developed up to the present time in favor of the view that there is not a definitely accumulative effect following the continued selection of fluctuating variations has been obtained from experiments on plants. There have been practically no systematic investigations of the effect of selection continued through many generations on higher animals, but it obviously is a matter of the greatest importance, both theoretically and practically, to determine in how far the principles which have been found to hold with reference to selection in plants also apply with reference to animals. The thorough investigation of the selection problem by Jennings referred to was, to be sure, carried out on an animal form, Paramecium, The method of reproduction in this protozoan form (fission) is. however, so different from sexual reproduction in vertebrates, that it must make one cautious (as Jennings himself is) about generalizing too extensively from these results. What is needed is a special investigation of the selection in a higher vertebrate. By preference this should be a domestic animal, because of the obviously great practical importance of questions involved. So far as we are aware the investigations which form the subject of the present paper, constitute the first experimental study of the effect of selection in a higher animal to be carried out with large numbers of individuals through a number of generations and with exact numerical records of the character studied in each individual.

\section{Plan of the Experiments.}

It is our purpose to discuss the results of two distinct and separate but supplementary experiments. These may be designated as follows:

I. Experiment in continued selection of fluctuating variations in fecundity.

II. Experiment regarding the inheritance of fecundity.

I. Experiment in continued selection of fluctuating variations in fecundity. In 1898 there was begun at the Maine Agricultural Experiment Station an experiment to determine whether egg production in the domestic fowl could be increased by the continued selection of the highest egg producers as breeders. This experiment was planned and started by Director C. D. Woods and the late Professor G. M. Gowell. An exact record was made of the 
egg production of each hen during the first year of her life; trap nests being used to furnish the individual records. In 1907 the records of egg production which had accumulated from the beginning of the experiment up to that time, were turned over to the present writers for analysis. The present paper sets forth certain of the results of the analysis made. The plan of the experiment begun in I898 was to make from a then superior strain of Barred Plymouth Rock hens, which had been pure bred for a long time by Professor Gowell, a continuous close and intense selection with reference to egg production. The practice in breeding was to use as mothers of the stock bred in any year only hens which laid between November I of the year in which they were hatched and November $I$ of the following year, I6o or more eggs. After. the first year, all male birds used in the breeding were the sons of mothers whose production in their first laying year was 200 eggs or more. Since the normal average annual egg production of these birds may be taken to be about I25 eggs, it will be seen that the selection practiced was fairly stringent.

Close inbreeding was not practiced. It was always possible to avoid this, since after the first few years of the experiment the flocks were very large (always containing more than 500 birds and usually nearer a thousand). While there was no close inbreeding no "new blood" was introduced into the strain from the outside during the period of the experiment.

While every effort was made to preserve uniform environmental conditions during the course of the experiment certain unavoidable environmental accidents occurred in certain of the laying years. These accidents may be held to have affected the egg production in those years adversely. Therefore, in discussing the results it will be necessary to make certain corrections for them. For a detailed account of their nature as well as for further details regarding the conduct of the experiment the more extensive report (loc. cit.) must be consulted.

II. Experiment regarding the inheritance of fecundity. In 1907 the experiment described above, having led to definite results was brought to an end. There was planned for 1908 a new experiment designed to test from another standpoint the conclusions which had been tentatively reached from the earlier experiment. In the conducting of the long selection experiment the females used as breeders were grouped into two classes, viz., (a) "unregistered" or birds laying I6o 
to I99 eggs in the pullet year, and (b) "registered" or birds laying 200 or more eggs in the pullet year.

It had been noted that the daughters of the socalled "registered" hens (namely hens that had produced 200 or more eggs each in the pullet year) did not usually make high egg records. The "200-egg" birds which made up the "registered" flock came, in most instances, from the "unregistered" mothers.

Experiment II was planned to answer the two following questions:

I. Will the daughters of high laying hens ("200-egg" birds) on the average produce more eggs in a given time unit than will birds of less closely selected ancestry?

2. What data do the performance records of such selected birds afford regarding the inheritance of fluctuating variations in egg producing ability in the domestic fowl?

The experiment was carried out according to the following plan: On the first of November, I907, there were put into House No. 2, of the Station plant, 250 pullets. Each of these was the daughter of a hen that had laid approximately 200 eggs in her pullet year. These 250 pullets were divided into flocks of 50 each and were fed and handled in every way exactly alike. At the same time that these 250 "registered" pullets (so-called because from "registered" mothers), were put into the house there were also put in 600 other Barred Plymouth Rock pullets. These other pullets were of approximately the same age as the $25^{\circ}$ "registered" pullets and differed in their breeding only in respect to their mothers. They came from hens that had laid less than 200 eggs during the pullet year and more than I6o. "Registered" cockerels (from the "200-egg line") were used as the male parents for all the pullets both "registered" and "unregistered". The 600 "unregistered" birds were divided into flocks as follows: Two flocks of 50 birds each were kept in two pens in House No. 2, exactly like the pens in which the "registered" birds were kept. The remaining 500 birds were divided into four flocks - two of roo birds each and two of 150 birds each and housed in the four pens of House No. 3. These pens are essentially like those of House No. 2, differing chiefly in the matter of size. A trap nest ${ }^{1}$ ) record was kept of the exact individual egg production of each of there birds.

1) For a description of the trap nest used in the breeding work of the Station see "Appliances and Methods for Pedigree Poultry Breeding" by R. Pearl and F. M. Surface. Me. Agric. Exp. Station. Bulletin No. I 59, pages 239-274. 1908. 
Chief Results of Selection Experiment I.

In considering the results of the long selection experiment $I$ the the three following questions present themselves as of first importance.

I. What is the general character of the variation exhibited in first-year egg production (fecundity) of the domestic fowl? Do we have here typical fluctuating variability?

2. Did the mean or average annual egg production per bird increase or decrease or remain unchanged during the course of the intensive and long continued selection practised in this experiment?

3. Was there any definite change in the variability of the flocks in respect to egg production during the course of the experiment? Did the birds come truer to type in respect to egg production at the end of the experiment than they did at the beginning?

Variation in Annual Egg Production. A careful biometrical analysis of variation in annual egg production (fecundity) was made with our data. The methods of Pearson were used in this analysis. Without going into detail regarding the results of this part of the work it may be said that the data warrant the following conclusions:

(a) Variation in egg production (fecundity) in the domestic fowl is, so far as can be determined, continuous and "fluctuating." It is of such character as to give rise to unimodal frequency curves, similar to those known for variation in other characters and organisms.

(b) The observed frequency polygons were all capable of satisfactory graduation by one or another type of Pearson's generalized probability curves. The values of the analytical constants obtained indicate that, in general, these poultry fecundity data demand limited range curves for their graduation. The majority of the curves are of Pearson's Type I (Skew curve of limited range).

c) The skewness or asymmetry of these variation curves is, generally speaking, not great, though in most cases significant in comparison with its probable error.

The most significant point for our present purpose is that in egg production we are dealing with a character which varies strictly in the usual or normal "fluctuating" continuous manner.

The general character of these variation curves may be illustrated by a single example. Figure I gives the frequency polygon and fitted curve for variation in egg production exhibited by 275 birds kept in flocks of 150 birds each in the laying year I905-06. 


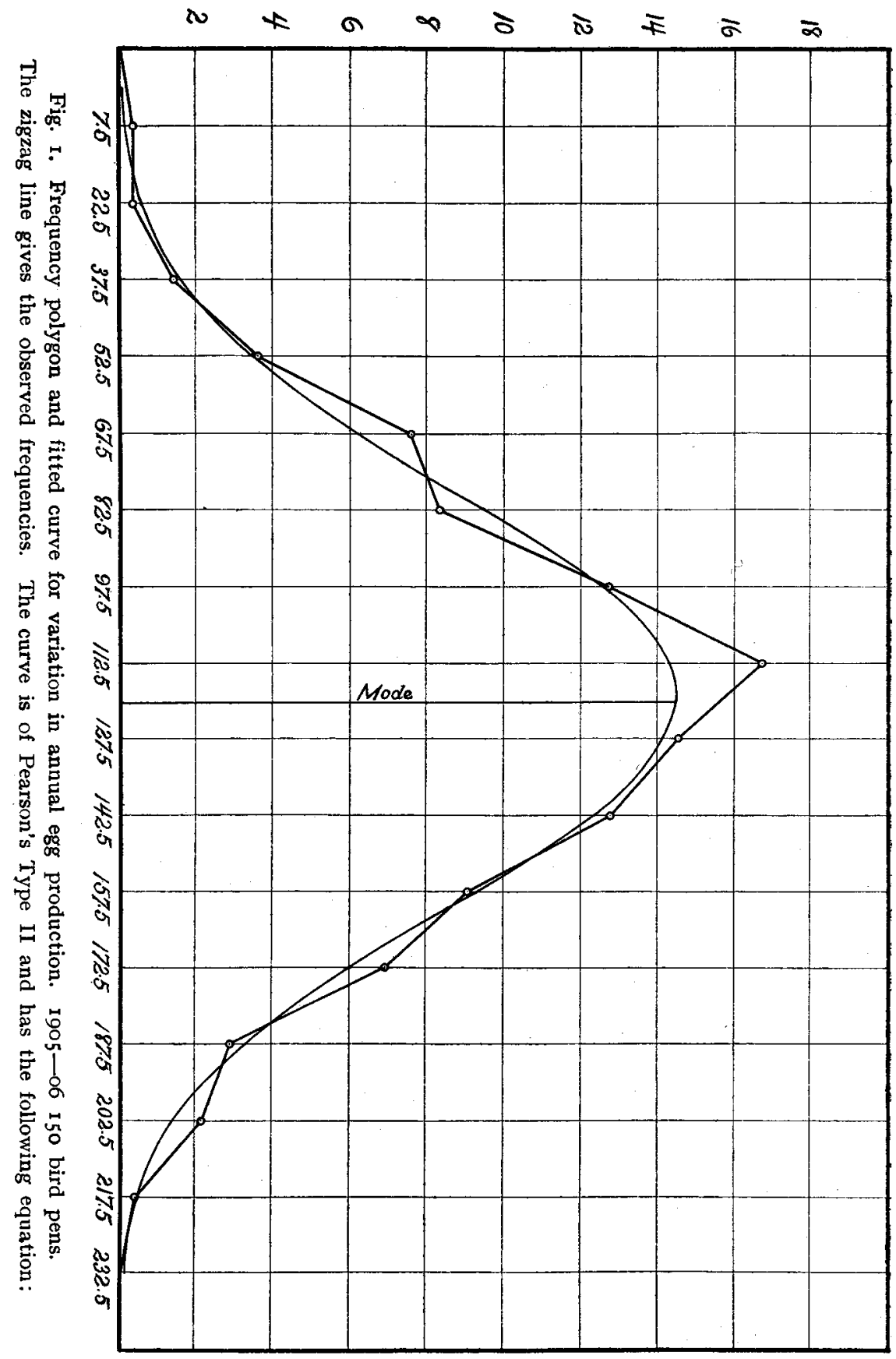




$$
y=39.86\left(\mathrm{I} \frac{\mathrm{x}^{2}}{\mathrm{I} 32 . \mathrm{I} 586}\right) 8.8636
$$

Results of continued selection for high egg production. The essential data giving the results of the selection carried out in this experiment are shown in Table I. This table gives for each year of the experiment the following data: (a) the actual mean or average egg production, (b) the modified average production, (c) the variability in regard to egg production as measured by the coefficient of variation, and (d) the number of birds included.

\section{Table I.}

Results of Selection Experiment I.

\begin{tabular}{|c|c|c|c|c|}
\hline $\begin{array}{l}\text { Laying } \\
\text { Year }\end{array}$ & $\begin{array}{l}\text { Observed Mean } \\
\text { Egg Production }\end{array}$ & $\begin{array}{l}\text { Modified } \\
\text { Mean Egg } \\
\text { Production }\end{array}$ & $\begin{array}{c}\text { Coefficient of } \\
\text { Variation }\end{array}$ & $\begin{array}{l}\text { Number of birds } \\
\text { furnishing data }\end{array}$ \\
\hline I $899-1900$ & I $36.36 \pm 3.55$ & I 36.36 & $32.29 \pm 2.02$ & 70 \\
\hline $1900-190 I$ & $143.44 \pm 3.29$ & I $43 \cdot 44$ & $31.38 \pm 1.78$ & 85 \\
\hline $190 I-190: 2$ & I $55.58 \pm 3.79$ & I $55.5^{8}$ & $25.03 \pm 1.83$ & 48 \\
\hline $1902-1903$ & $136.48 \pm 2.19$ & I 59. I 5 & $28.82 \pm 1.22$ & 147 \\
\hline $1903-1904$ & 1 $7.87 \pm 1.75$ & $\mathrm{I} 29 . \mathrm{I} 4$ & $35.14 \pm 1.17$ & 254 \\
\hline $\left.1904-1905^{1}\right)$ & $134.60 \pm 1.98$ & 134.07 & $36.77 \pm I .17$ & 283 \\
\hline I905-I9061) & $140.3 \mathrm{I} \pm \mathrm{I} .8 \mathrm{I}$ & I 54.09 & $25.4^{8} \pm 0.97$ & 178 \\
\hline $\left.1906-1907^{1}\right)$ & I $14.16 \pm 1.74$ & $142: 77$ & $30.91 \pm 1.18$ & 187 \\
\hline
\end{tabular}

The data of Table I are shown graphically in figs. 2 and 3 . Figure 2 shows the change in the observed and modified averages, and the best fitting straight lines to these data, as determined by the method of least squares, Figure 3 shows the change in the variability of the flocks (coefficient of variation), the observational data again being smoothed by a straight line fitted by the method of least squares.

$$
\begin{array}{ll}
\text { Observed means } \mathbf{y}=148.48-3.10 \quad \mathbf{x} \\
\text { Modified } " \quad \mathbf{y}=144.13+0.043 \mathbf{x} \\
\text { Variability } \quad \mathbf{y}=30.56+0.039 \mathbf{x}
\end{array}
$$

where $\mathbf{x}$ denotes the year.

From the data of Table I and Figures 2 and 3 we note the following points:

1) Data for birds kept in flocks of 50 birds each used in these years. The reasons for this procedure are given in the detailed report q. $v$. 
x. There was no definite increase in mean annual egg production during the period of eight years covered by the statistics. As is to be expected, there are up and down fluctuations in the several years, but the general trend of the means, as indicated by the fitted straight lines in Fig. 2, is certainly not upward. Taking the actual means the trend of the line is clearly downward. The line for the modified

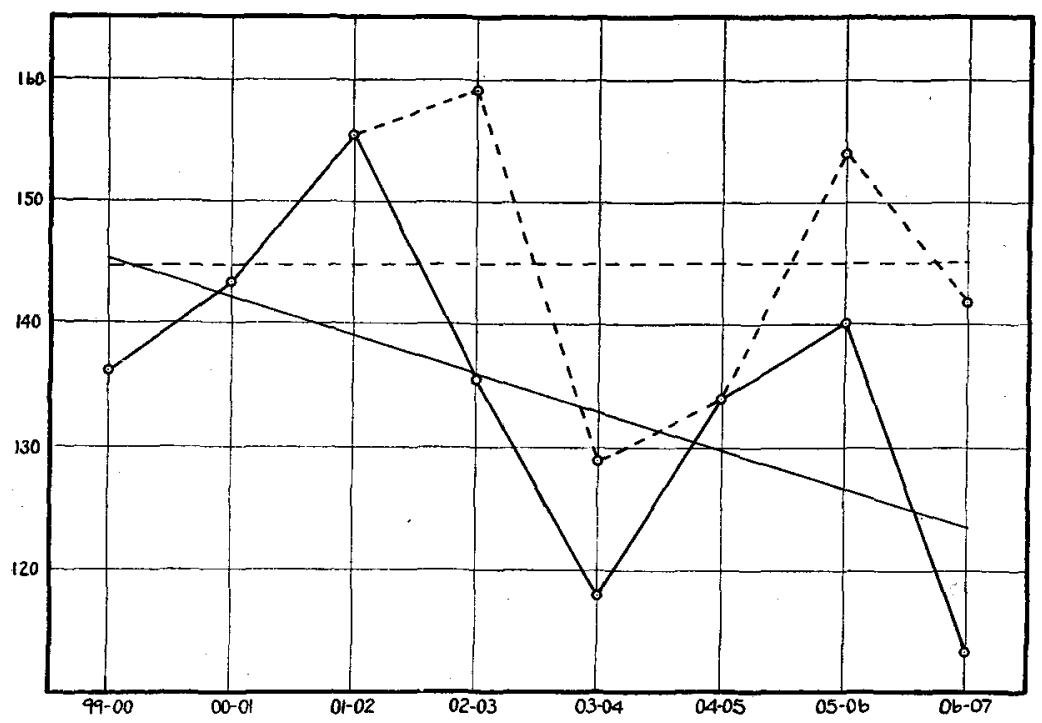

Fig. 2. Diagram showing change in mean egg production during the progress of the selection experiment. The unbroken lines give the observed means, and the dotted lines the modified means.

means is horizontal. There is no evidence whatever of any cumulative effect of the selection practised.

2. The general trend of the variability as shown by the fitted line in Figure 3, is slightly to increase during the course of the experiment. No stress is to be laid on this slight increase. The important thing is that there is no evidence whatever of any decrease in relative variability as a result of the long continued and intensive selection.

Chief Results of Selection Experiment II.

The plan and purpose of this experiment have been stated above (p. 262) and need not be here repeated. We may first consider the the question as to what evidence the experiment furnished regarding the inheritance of fluctuating variations in egg production. The 
comparative figures for the egg production of mothers and daughters are given in Table II. In discussing the results of this experiment the egg production of the winter months (November I to March I) and of the spring months (March I to June I, the natural mating and breeding season of the birds) will be considered separately.

From the data set forth in this table and additional ones given in the detailed report the conclusions given below may be drawn. It will be understood that considerations of space forbid giving here the entire evidence on which these conclusions rest. For the detailed

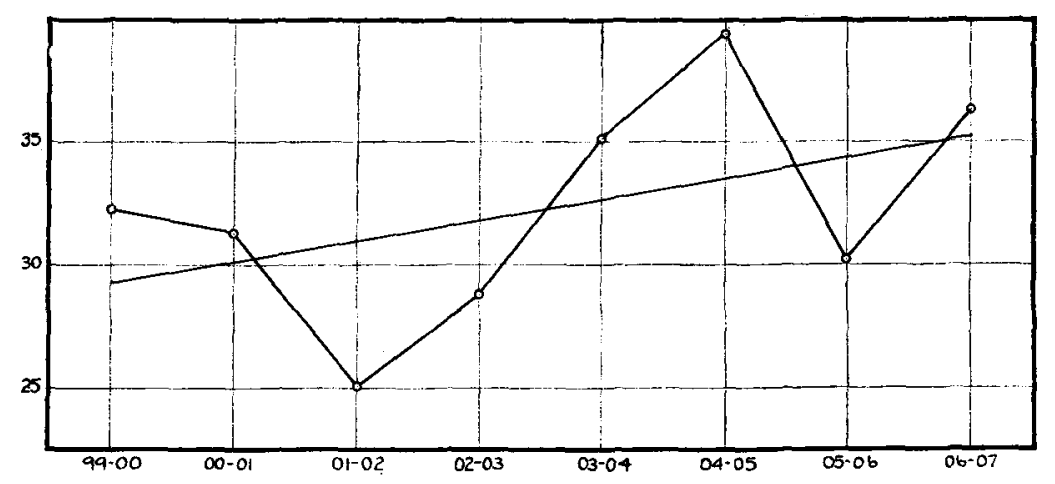

Fig. 3. Diagram showing change in variability of flocks in egg production during the course of the selection experiment. The zigzag line gives the observed coefficients of variation.

presentation and critical analysis of this evidence the complete papers already referred to (p. 257 supra) must be consulted.

I. The daughters of "200-egg" or "registered" hens are markedly inferior to their mothers in egg production for both of the periods studied. This difference is particularly great in the winter (Nov. I March I) period. It is evident that the daughters do not belong in anything like the same class as the mothers as winter egg producers. The mothers' average production for the corresponding period of their pullet year was nearly 4 times as great as the daughters'. (Exactly $45.5 \div 12.7=3.7$.) This great reduction of the daughters' average winter production below the mothers' is most striking and unexpected. It is to be expected on general grounds that there would be some regression, but so much as this would hardly have been anticipated.

2. Quite apart from the question of the average production of mothers and daughters the data gives no indication that there is any sensible correlation between individual mothers and individual daughters 
Pearl and Surface.

Table II.

Showing the Egg Records of "Registered" Hens and the Number and Egg Records of Their Daughters.

\begin{tabular}{|c|c|c|c|c|c|c|c|c|}
\hline \multirow{2}{*}{ 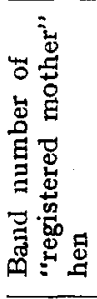 } & \multirow{2}{*}{ 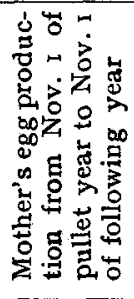 } & \multicolumn{3}{|c|}{$\begin{array}{l}\text { Number of daughters } \\
\text { of each "registered" } \\
\text { hen in the experiment }\end{array}$} & \multicolumn{2}{|c|}{$\begin{array}{c}\text { Winter egg } \\
\text { production } \\
\text { Nov. I-Mar. I }\end{array}$} & \multicolumn{2}{|c|}{$\begin{array}{c}\text { Spring egg } \\
\text { production } \\
\text { Mar. I-June I }\end{array}$} \\
\hline & & Total & 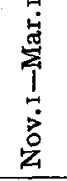 & 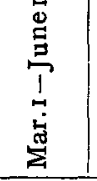 & Mother's & $\begin{array}{c}\text { Daughter's } \\
\text { average }\end{array}$ & Mother's & $\begin{array}{c}\text { Daughter's } \\
\text { average }\end{array}$ \\
\hline 7 & 193 & 12 & 12 & I 2 & 33 & 14.83 & $8 \mathrm{I}$ & 47.75 \\
\hline 33 & 192 & 8 & 8 & 8 & 30 & I 3.37 & 68 & 53.25 \\
\hline 578 & 196 & 4 & 4 & 4 & 42 & 23.75 & 59 & 42.25 \\
\hline 253 & 200 & 9 & 8 & 7 & 65 & 23.87 & 45 & $3^{8.14}$ \\
\hline $4^{6}$ & 184 & 3 & 3 & 3 & 64 & I 5.33 & 56 & 51.00 \\
\hline 460 & 208 & 8 & 8 & 8 & 61 & $15.5^{\circ}$ & 60 & 44.87 \\
\hline 617 & 183 & 4 & 4 & 4 & 47 & 5.25 & 56 & 38.00 \\
\hline $4^{2}$ & 216 & 7 & 7 & 6 & 46 & 13.28 & 67 & 52.83 \\
\hline 169 & 210 & 17 & I 5 & I 5 & 70 & I 3.47 & 54 & 44.43 \\
\hline I 50 & 193 & 5 & 5 & 5 & 56 & 18.00 & 53 & 50.80 \\
\hline 236 & 180 & 7 & 6 & 5 & 24 & 20.83 & 62 & 46.20 \\
\hline I 52 & 200 & 6 & 6 & 6 & 49 & 18.83 & 69 & $43 \cdot 33$ \\
\hline 105 & 217 & 8 & 8 & 8 & 68 & 17.25 & 66 & 48.12 \\
\hline 386 & 203 & 9 & 9 & 9 & 55 & 4.88 & 59 & 40.88 \\
\hline 9II & 196 & 3 & 3 & 3 & 52 & $27 \cdot 33$ & 62 & $55 \cdot 33$ \\
\hline 510 & 212 & 3 & 3 & 2 & 69 & 0.00 & 59 & I $2.5^{\circ}$ \\
\hline 404 & 203 & 2 & 2 & 2 & 55 & $19.5^{\circ}$ & 56 & 62.00 \\
\hline 174 & 208 & 6 & 6 & 6 & 43 & 24.00 & 68 & 44. I 6 \\
\hline 166 & $22 \mathrm{I}$ & 7 & 7 & 7 & 66 & 7.14 & 56 & 46.57 \\
\hline 2 & I9O & Io & Io & Io & $4^{8}$ & 17.90 & 60 & 45.80 \\
\hline 505 & 204 & 6 & 6 & 5 & 58 & 17.66 & 43 & $3^{8.00}$ \\
\hline 464 & 202 & 7 & 7 & 7 & 77 & 19.57 & 62 & 51.28 \\
\hline 32 & 203 & 9 & 9 & 9 & 64 & 11.00 & 55 & $50 \cdot 33$ \\
\hline I I I & $?$ & IO & - & - & - & - & & - \\
\hline 379 & 203 & 4 & 4 & 4 & 63 & 24.25 & 66 & $47.5^{\circ}$ \\
\hline r 30 & 208 & 3 & 3 & 3 & 68 & 14.00 & $5 \mathrm{I}$ & 53.00 \\
\hline 49 & 200 & 4 & 4 & 3 & 29 & 18.00 & 65 & $42 \cdot 33$ \\
\hline 351 & 201 & .5 & 5 & 5 & 68 & I 5.20 & 49 & 53.80 \\
\hline & I 86 & 8 & 7 & 7 & 60 & 14.14 & 49 & 59.85 \\
\hline 614 & $?$ & 9 & - & - & - & - & - & - \\
\hline $\mathrm{I} 4$ & 197 & 6 & 5 & 4 & 66 & 2.40 & 68 & 47.75 \\
\hline 349 & 203 & 4 & 4 & 3 & 51 & 10.25 & 55 & $37 \cdot 33$ \\
\hline 303 & 246 & 4 & 4 & 4 & 83 & 7.25 & 60 & 29.70 \\
\hline 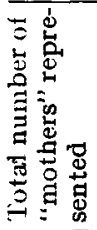 & 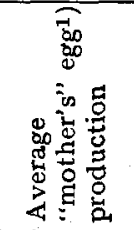 & & Total & & 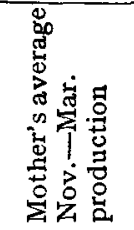 & 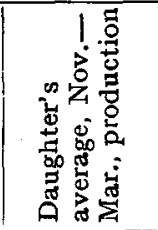 & 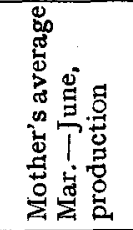 & 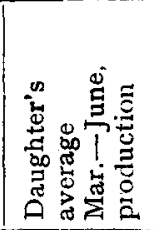 \\
\hline 33 & 201.8 & 217 & 192 & I 84 & 55.80 & 15.29 & 59.13 & 46.61 \\
\hline
\end{tabular}

1) Omitting the two birds without records, No. III and No. 6I4. 
in respect to egg production. It is quite conceivable that the
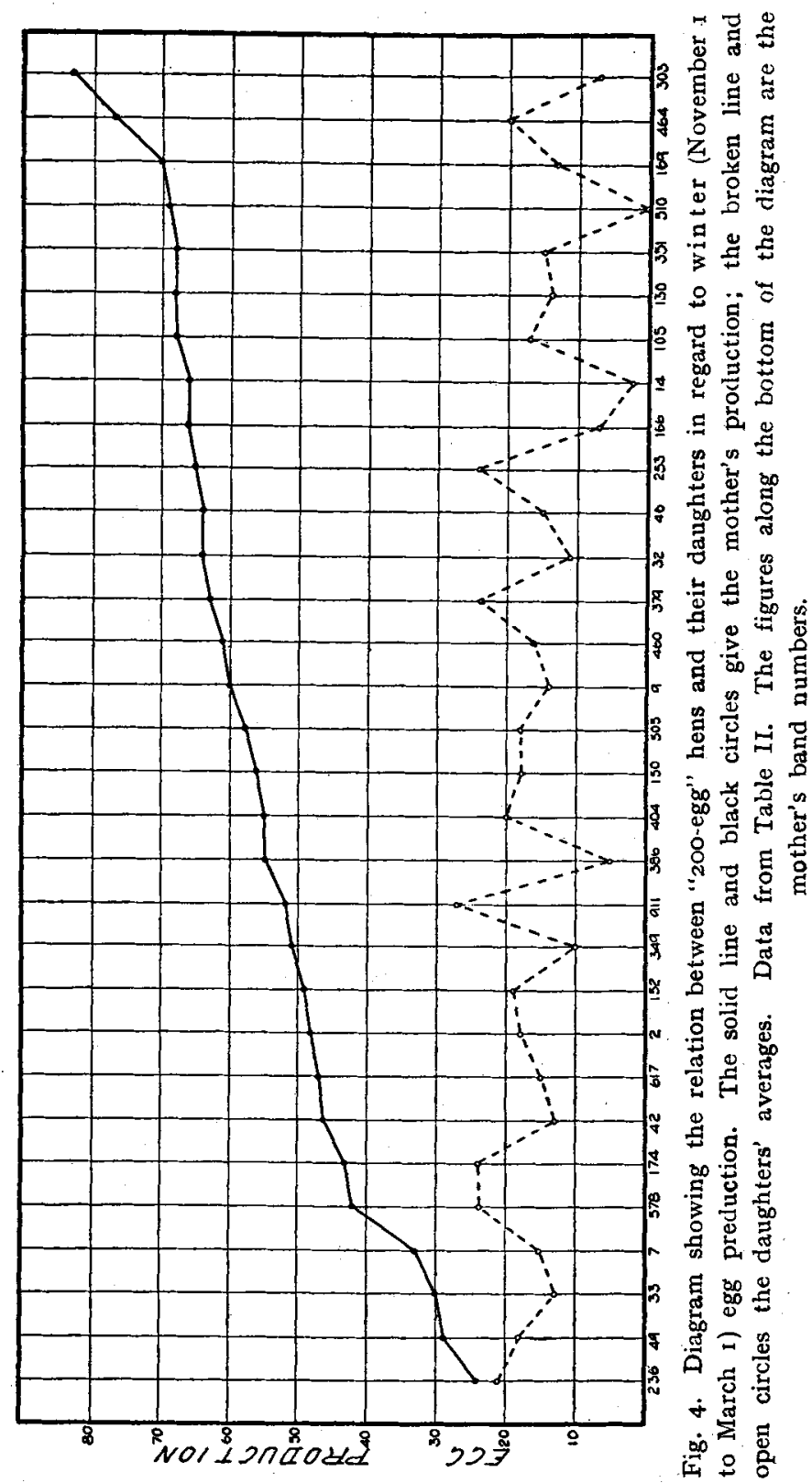

daughters' average production might be very much lower than their mothers' average production and there still be inheritance of the egg 
producing ability. This seeming paradox might arise in this way. If unfavorable environmental influences acted in the case of daughters the average production of the whole group of daughters might be considerably below that of the mothers. At the same time the exceptional mother (that is the mother whose production was above the average for mothers) might produce the exceptional daughter (the daughter whose performance was above the average for daughters). Such a condition of affairs would obviously indicate the inheritance of egg producing ability and yet clearly might exist quite independently of the relative magnitude of the averages of the mother and daughter groups as wholes.

To determine whether there is such an inheritance of egg producing ability independent of the group averages it is necessary that the correlation between mothers and daughters in respect to egg production be actually measured. From such measurement it can be told whether on the average the exceptional mother produces the exceptional daughter or whether the exceptional daughter is as likely as not to be the daughter of the mediocre or poor mother.

Such correlations have been determined for each laying period. The net result is to show that in this material there is no sensible correlation between mother and daughter in respect to egg production. In other words there is no evidence that fluctuating variations in this character were inherited in the mass in this experiment. This lack of correlation is shown graphically in Fig. 4 which compares mothers and daughters in respect to winter egg production. If there were an inheritance of fecundity it would be expected that the two zigzag lines in this figure would take a more or less parallel course. This they obviously do not do.

Turning to the question as to whether the daughters of "200-egg" hens were or were not better egg producers than other birds not of such highly selected ancestry (see p. 262 supra) when kept under identical environmental conditions we have the comparative figures given in Table III.

From the table it appears that:

I. With a single exception where the difference is very small (roo bird pens) the mean production of the "unregistered" (less closely selected) birds was in all cases higher than that of the "registered" (more closely selected) birds. In other words the data show that the daughters of "200-egg" hens are certainly not 
Is there a Cumulative Effect of Selection?

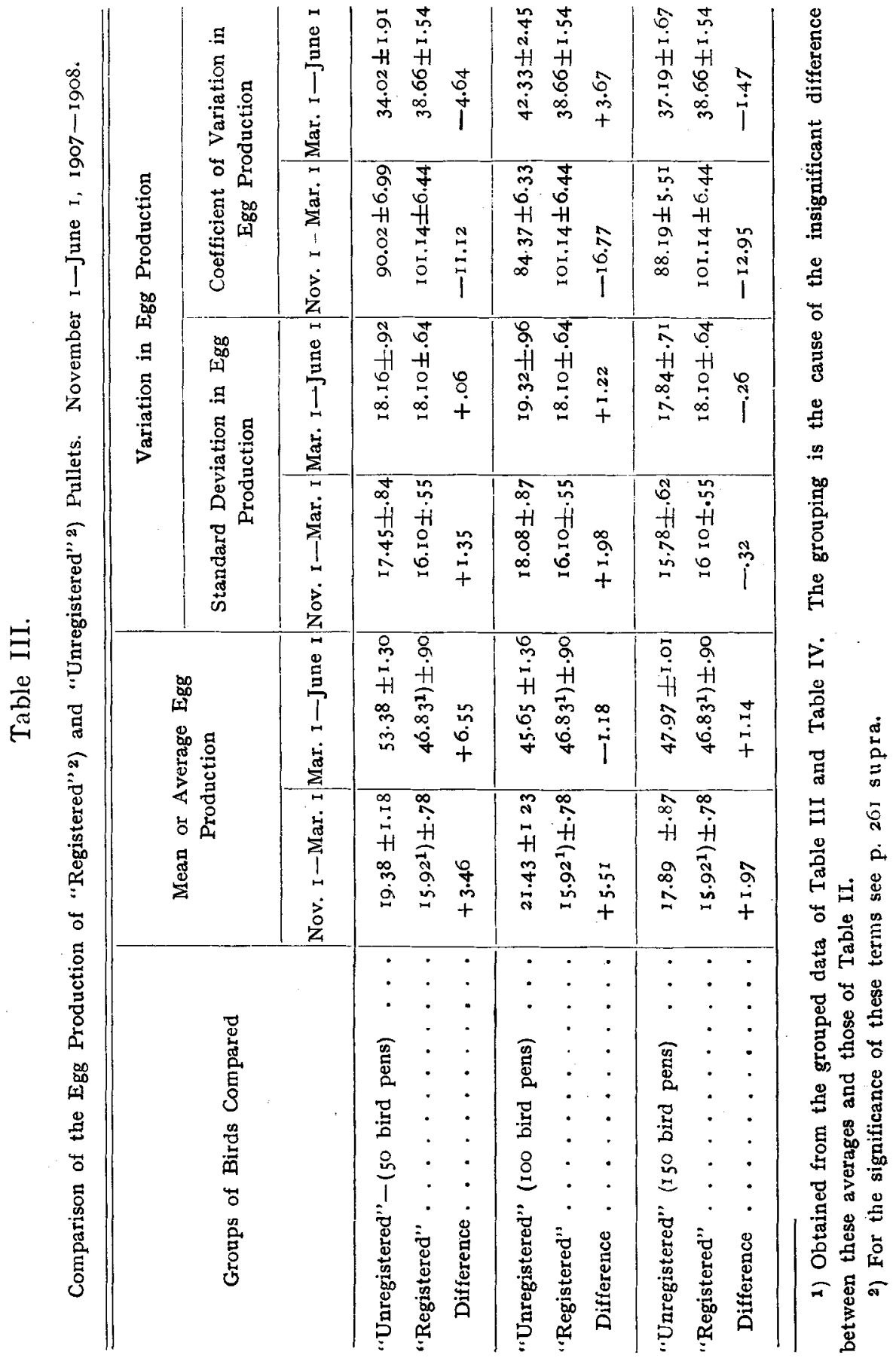


higher producers than other pullets of less intensely selected ancestry.

2. The coefficients of variation clearly show that the "unregistered" birds are relatively less variable than the "registered." There is only one exception to this rule and the difference in that case is very small. This means that the daughters of "200-egg" hens instead of conforming more closely to a particular type of egg production, as would on general grounds be expected, actually conform less closely to type than do birds of less closely selected ancestry.

\section{Discussion of Results.}

The answer given by the investigations here summarized to the questions stated as the title of this paper is definite and clear. So far as the character fecundity (egg production) in the domestic fowl is concerned long continued and carefully executed experiments give no evidence whatever that there is a cumulative effect of the selection of fluctuating variations.

The facts brought out by this work indicate clearly enough that all birds which have equal records of performance in respect to egg production are not alike in their ability to transmit fecundity. Judged by the performance of their offspring a group of "200-egg" hens, while very homogeneous so far as performance records are concerned, must be very heterogeneous in regard to the constitution of the germ cells relative to the character fecundity. Some "200-egg" hens are apparently capable of producing offspring with very high laying capacity (cf., data in Table II). Other "200-egg" hens exactly similar in all observable respects lack this capability. These facts are of exactly the same order as those which have been brought out by Mendelian work, showing that the constitution of the soma furnishes no certain criterion of the condition or constitution of the germ cells.

But the assumption, tacit or expressed, which lies at the foundation of mass selection methods in practical breeding is that the soma does as a matter of fact give a working criterion of the constitution and potentialities of the germ cells. One breeds from the superior individuals in regard to somatic characters because he expects that the offspring will be superior. Is this expectation well founded? Altogether much evidence is accumulating from widely different sources to show that simple selection of superior individuals as breeders can not alone be depended upon to insure definite or 
continued improvement in a strain. Some improvement may possibly follow this method of breeding at the very start but the limits both in time and amount are very quickly reached. In support of this view of the possibilities of selective breeding the results set forth in the present paper furnish definite and positive confirmatory evidence. Our experience shows that in order to establish a strain of hens in which high egg production shall be a fixed characteristic it is necessary to do something more than simply breed from high producers. It will of course be understood that our investigations are not stopping at this point. It is proposed to test the conclusions stated in this paper in every possible way.

That greatly exaggerated ideas as to the effectiveness of continued selection of fluctuating variations in improving stock have been widely held during the last half century admits of no doubt. Yet many practical breeders have clearly understood that something more than this was necessary to insure certain and definitely fixed improvement. In this connection a statement from a chapter on. "Selection" in an old work ${ }^{1}$ ) containing much interesting matter concerning current opinion of the time on breeding questions is worth quoting. After outlining briefly the general plan of selective breeding the author goes on to say: "It is not merely by putting the best male to the best female, that the desired qualitites can be obtained; but by other means not clearly defined in the common practice." May it not fairly be said that, as a result of the work of Nilsson, De Vries, Johannsen and others, some at least of these "other means" are now coming to be "clearly defined"?

The results set forth in this paper raise in one's mind some doubt as to the validity of the explanation commonly given for the superiority of present day races of poultry over the wild Gallus bankiva in regard to egg production. It is generally held that the reason for this superiority lies in the continued selection for increased egg production which is assumed to have been practised during the centuries since the domestication of poultry began. Critical examination of this explanation indicates, however, that it has some very weak points. The following considerations are significant in this connection.

1) Walker, A. Intermarriage: or the Mode in which, and the causes why, Beauty, Health and Intellect result from certain Unions and Deformity, Disease and Insanity from others: Demonstrated by .... and by an account of corresponding Effects in the Breeding of Animals. American Edition, New York 1839. 
I. It is an assumption for which we have been able to find little historical warrant to say that selection for egg production was systematically or generally practised with poultry before sometime in the first half of the nineteenth century. Yet there are definite and, by all tests possible to make, authentic records of egg production as high as anything we now know, but made before 1800 .

2. The definite experimental results set forth in the present paper do not afford any evidence that it is possible to increase egg production by mass selection methods.

3. There is evidence that the explanation for the superior egg production in the domesticated as compared with the wild Gallus lies in the effect of the environmental influences comprised in the process and conditions of domestication itself. This evidence consists in the known fact that wild birds other than Gallus when put under conditions of domestication have their egg production immediately increased over what it was in the wild state, without the intervention of any selective breeding whatever. We may cite here two instances in support of these statements. The first has to do with the wild Mallard duck (Anas boschas) in captivity. Mr. E. H. Austin ${ }^{1}$ ), who makes a specialty of domesticating wild water fowl and has had much experience in this direction makes the following statement: "The Mallard duck in the wild state lays I2 to 18 eggs. In captivity it will lay 80 to Ioo if the bird in confined at night in a pen and has liberty (in pond or large enclosure) during the day, and the eggs removed daily. As far as my experience goes this is the case with no other variety of duck. The others will desert their nest and stop laying if their eggs or nest are troubled. The Mallard is the original ancestor of the Rouen ducks, and when taken into captivity grows large and coarse in a few generations. It is necessary to constantly use wild drakes to maintain the fine lines and graceful carriage of the wild bird."

A similar condition of affairs has recently been recorded by Duerden ${ }^{2}$ ) for the ostrich, a bird which has certainly not been selected for egg production during its period of domestication. This. investigator states as one of the results of his stury of some ostrich egg records that: "The numbers show that ostriches, like poultry,

- 1) Austin, E. H. Original Laying Capacity. Farm-Poultry (Boston) Vol. XIX, p. 347, I908.

2) Duerden, J. E. Experiments with Ostriches. VI - Egg - laying Records. of Ostriches. Agricultural Journal (Cape of Good Hope) April, Igo8. 
will go on laying almost continuously during the breeding season, if the eggs are removed as laid, and the birds are not allowed to sit." He further shows that, just as with poultry, the environmental conditions under which the birds are kept have a marked influence on the egg production in ostriches.

In general we are strongly inclined to the view that the existing evidence indicates that the superior egg production of present-day races of domestic poultry is in the main the result of the action of the favorable environmental influences included in the process and conditions of domestication, rather than an effect of the selection of favorable fluctuating variations through a long period of time.

\section{Summary.}

The data discussed in this paper were obtained from two lines of work. The first of these was an experiment in which for a period of nine years hens have been selected for high egg production. No hens were used as breeders whose production in the pullet year had not been r6o or more eggs. The cockerels used were, after the first year of the experiment, invariably the sons of mothers producing 200 or more eggs in their pullet year.

The second source of data was an experiment in which the inheritance of egg production from mother to daughter was directly measured. Records of the pullet year egg production of 250 daughters of hens laying 200 or more eggs in their (the mothers') pullet year were obtained.

Certain of the most important results obtained may be summarily stated as follows: -

I. Selection for high egg production carried on for nine consecutive years did not lead to any increase in the average production of the flocks.

3. There was no decrease in variability in egg production as a result of this selection.

3. The present data give no evidence that there is a sensible correlation between mother and daughter in respect to egg production, or that egg-producing ability (fecundity) is sensibly inherited.

4. In this experiment the daughters of " 200 -egg" hens did not exhibit, when kept under the same environmental conditions, such as high average egg production as did pullets of the same age which were the daughters of birds whose production was less than 200 eggs per year.

5. The daughters of "200-egg" hens were not less variable in respect to egg production than were similar birds whose mothers were not so closely selected. 